\title{
Removal of airborne hexavalent chromium using alginate as a biosorbent
}

\author{
${ }^{1}$ A. Tirgar; ${ }^{2 *}$ F. Golbabaei; ${ }^{3}$ J. Hamedi; ${ }^{4}$ K. Nourijelyani \\ ${ }^{1}$ Department of Social Medicine, School of Medicine, Babol University of Medical Sciences, Babol, Iran \\ ${ }^{2}$ Department of Occupational Health, School of Public Health and Institute of Public Health Research, Tehran \\ University of Medical Sciences, Tehran, Iran \\ ${ }^{3}$ Microbial Biotechnology Laboratory, School of Biology, College of Science, University of Tehran, Tehran, Iran \\ ${ }^{4}$ Department of Epidemiology and Biostatistics, School of Public Health and Institute of Public Health Research, \\ Tehran University of Medical Sciences, Tehran, Iran
}

Received 5 July 2010; $\quad$ revised 25 December 2010; accepted 6 January 2011; available online 1 March 2011

\begin{abstract}
Airborne hexavalent chromium has been classified as a human respiratory carcinogen and long term exposure has been known to cause ulceration and perforation of the nasal septum, bronchitis, asthma, and liver and kidney damage. Chromium electroplating plants are the major sources of atmospheric chromium and packed-bed scrubbers are the common control devices used to reduce emission of chromic acid mist from electroplating bathes. The feasibility of a new method to remove this pollutant using alginate beads as a biomass derivative was investigated by one factor at a time approach and Taguchi experimental design. Polluted air with different chromium mist concentrations (10-5000 $\mu \mathrm{g} / \mathrm{m} 3)$ was contacted to alginate beads $(3.3-20 \mathrm{~g} / \mathrm{L})$, floating in distilled water with adjusted $\mathrm{pH}$ (3-7), using an impinger at different temperatures (20 and 35oC), and various velocities $(1.2$ and $2.4 \mathrm{~m} / \mathrm{s}$ ). Although there were no statistical significant differences between factor levels, the higher ions removal efficiencies were achieved at lower levels of air velocities, pollution concentrations, higher levels of $\mathrm{pHs}$, temperatures, and sorbent concentrations.
\end{abstract}

Keywords: Alginat; Biosorbent; Chromium mist; Control; Electroplating; Novel system

\section{INTRODUCTION}

Hexavalent chromium, $\mathrm{Cr}(\mathrm{VI})$, has been classified as a human respiratory carcinogen and allergen (Ashley et al., 2003; Guertin et al., 2005; Hara et al. 2010; Nickens et al., 2010). Long term exposure to airborne $\mathrm{Cr}(\mathrm{VI})$ has been known to cause ulceration and perforation of the nasal septum, bronchitis, asthma, and liver and kidney damages in exposed workers (Kumar et al., 2005; Costa and klein, 2006). $\mathrm{Cr}$ (VI) emission is associated with a number of industrial sources including metal plating, tanning, chromate ore processing and spray painting operation; combustion sources such as automobiles and incinerators (Ashley et al., 2003; Park et al., 2004; Babel and Opiso, 2007; Pandey et al., 2010). Thus, controlling of chromium emission is an important issue

*Corresponding Author Email: gol128@sphtums.com

Tel.: +98216646 5404; Fax: +982166462267 in both industrial hygiene and environmental protection (Nwachukwu et al., 2010).

Chromium electroplating plants are the major sources of atmospheric chromium (Kuo and Wang, 2002; OSHA 2006; Tirgar et al., 2007), and Packed-Bed Scrubbers (PBS) are the common controlling devices used to reduce emission of chromic acid mist from electroplating bathes. Such industries should spend considerable money for scrubber wastewater treatment. Treatment of industrial effluents having less than about $0.1 \mathrm{~g} / \mathrm{L}$ of dissolved metal ions by conventional processes presents several disadvantage, such as high operational cost, low efficiency, and generation of solid waste-often toxic, that may require safety disposal protocols or even further treatment (Ibanez and Umetsu, 2002; Aliabadi et al., 2006; Abdel-Ghani and Elchaghaby, 2007; Goyal et al., 2008; Nameni et al., 2008). 
The capacity of biological entities to uptake heavy metal ions from dilute aqueous solutions is well documented and it can be considered as an alternative to be used under conditions where conventional processes lost competitiveness (Park and Park, 2006; Rafati et al., 2010; Sethuraman and Balasubramanian, 2010; Vinodhini and Das, 2010). The biological treatment could be an alternative method to clean-up industrial wastewaters containing heavy metals. However, these processes are very sensitive to the characteristics of the effluent, as temperature, $\mathrm{pH}$ and chemical composition.

The use of dead biomass and biomass derivatives (biosorbent materials) for removal of heavy metals from aqueous solutions has been widely studied in recent years. These systems are less expensive than the traditional physicochemical processes. They do not need nutrients and are resistant to the physicalchemical properties of heavy metal solutions (Araujo and Teixeira, 1997).

Alginate, an exopolymer extracted mainly from brown seaweeds, has been used for a long time in several industrial applications. Among recent application, alginate has been used as a cell immobilization material and as a biosorbent material for removal of divalent heavy metals, such as $\mathrm{Cu}^{2+}$, $\mathrm{Co}^{2+}, \mathrm{UO}^{2+}$ and $\mathrm{Zn}^{2+}$ from aqueous solutions. Alginate showed good metal sorption efficiency (Araujo and Teixeira, 1997; Veglio et al., 2002).
There are few reports about airborne heavy metal removal using a biomass derivative. Thus, in this project, alginate beads efficiency (as a biosorbent) for airborne $\mathrm{Cr}(\mathrm{VI})$ removal was studied in Public Health School and Public Health Research Institute, Tehran University of Medical Sciences, Iran (2006-7). The aim of this work was to investigate the feasibility of developing a method to remove airborne $\mathrm{Cr}$ (VI) mist.

\section{MATERIALS AND METHODS}

\section{Airborne Cr (VI) generation}

The predominant constituent in chromiumelectroplating bath is $\mathrm{CrO}_{3}$, although these might be amount of additives (usually $1 \% \mathrm{H}_{2} \mathrm{SO}_{4}$ ) used in shop (Kuo and Wang, 1999). Thus, an electroplating bath was prepared as the source of $\mathrm{Cr}$ (VI) mist emission in pilot scale (Fig. 1). Detail of this system which equipped with a special sampling chamber and had a homogenous airborne $\mathrm{Cr}$ (VI) atmosphere, has been reported in our previous paper (Tirgar et al., 2006a).

\section{Chemicals}

Sodium alginate [Sigma-Aldrich Co.] was used. All the other chemicals were analytical grade and purchased from Merck Co.

\section{Beads preparation}

Calcium alginate beads were prepared by dropping a $3 \%(w / v)$ sodium alginate aqueous solution to a


A: Rectifier, B: Cathode, C: Anode, D: Electroplating bath, E: Anti acid pump, F and G: Valves, H: Plexiglas case (sampling chamber) I: Hood

Fig. 1 : Set up of the mist generation system and sampling chamber 
stirred $2 \%(\mathrm{w} / \mathrm{v}) \mathrm{CaCl}_{2}$, solution. Beads were stirred in $\mathrm{CaCl}_{2}$ solution on the orbital shaker at $250 \mathrm{rpm}$ for 24 hours. Then, they were washed three times with distilled water and kept in a $2 \% \mathrm{CaCl}_{2}$ solution at $4{ }^{\circ} \mathrm{C}$. Immediately before use, the calcium alginate beads were washed again three times with distilled water and the excess water was absorbed on paper filter (Araujo and Teixeira, 1997; Göksungur, et al., 2003).

\section{Bead characterization}

The mean diameter of beads was determined in 10 groups of 50 alginate beads using a micrometer $(2.87 \pm 0.06 \mathrm{~mm})$. The mean weight of the beads was determined using 10 samples of 20 beads $(14.81 \pm 0.71$ $\mathrm{mg})$. The solid content of the alginate beads were weighted before and after drying [7.04 $\pm 0.32 \%(w / w)]$. The biosorbent was dried in an oven at $60^{\circ} \mathrm{C}$ over night (for $24 \mathrm{~h}$ ).

\section{Metal binding capacity}

In order to find out optimum removal condition and Cr (VI) binding capacity, two sampling trains were used simultaneously (Fig. 2).

\section{Sampling train with biosorbent}

Sampling train with biosorbent (Biosorbent train) consisted of the following compartments: A) a special and standard air sampler named Midget Impinger (SKC, Blandford Forum, UK) containing alginate beads and $15 \mathrm{~mL}$ water with adjusted $\mathrm{pH}$ in thermostatically controlled water bath (Fig. 2). B) a 37-mm polystyrene filter cassette (part B) containing a $5.0 \mu \mathrm{m}$ pore size polyvinyl chloride (PVC) membrane filter (MSA, Pittsburgh, USA). C) a personal sampling pump (Model 224-PCXR3; SKC, Blandford Forum, UK) calibrated for air flow rate of 1 or $2.0 \pm 0.1 \mathrm{~L} / \mathrm{min}$.

\section{Sampling train without biosorbent}

Sampling train without biosorbent (Water train) was completely the same as biosorbent train except Midget Impinger contained $15 \mathrm{~mL}$ only water with adjusted similar $\mathrm{pH}$. Sampling duration for all samples were the same, i.e. $60 \mathrm{~min}$.

The difference between chromium concentration in biosorbent train and water train was considered as alginate-bounded chromium. The percent of adsorbed chromium ions was evaluated as $[(\mathrm{CW}-\mathrm{CB}) / \mathrm{CW}] \times 100$. $\mathrm{CW}$ and $\mathrm{CB}$ are the concentration of the metal ions in the water and biosorbent solution $(\mathrm{mg} / \mathrm{L})$ after sampling, respectively.

Optimization of biosorption conditions by one factor at a time approach

Effect of $\mathrm{pH}$ on the biosorption rate was investigated in the $\mathrm{pH}$ range 3.0-7.0. The $\mathrm{pH}$ was adjusted with $0.1 \mathrm{M} \mathrm{HNO}$ or $\mathrm{NaOH}$ at the beginning of the experiments. The effect of pollutant concentration was studied at three different levels (low, medium, and high) between $10-5000 \mu \mathrm{g} / \mathrm{m}^{3}$. Also the effect of biosorbent concentration was determined at three different levels $(3.3,10$, and 20 $\mathrm{mg} / \mathrm{mL}$ ).

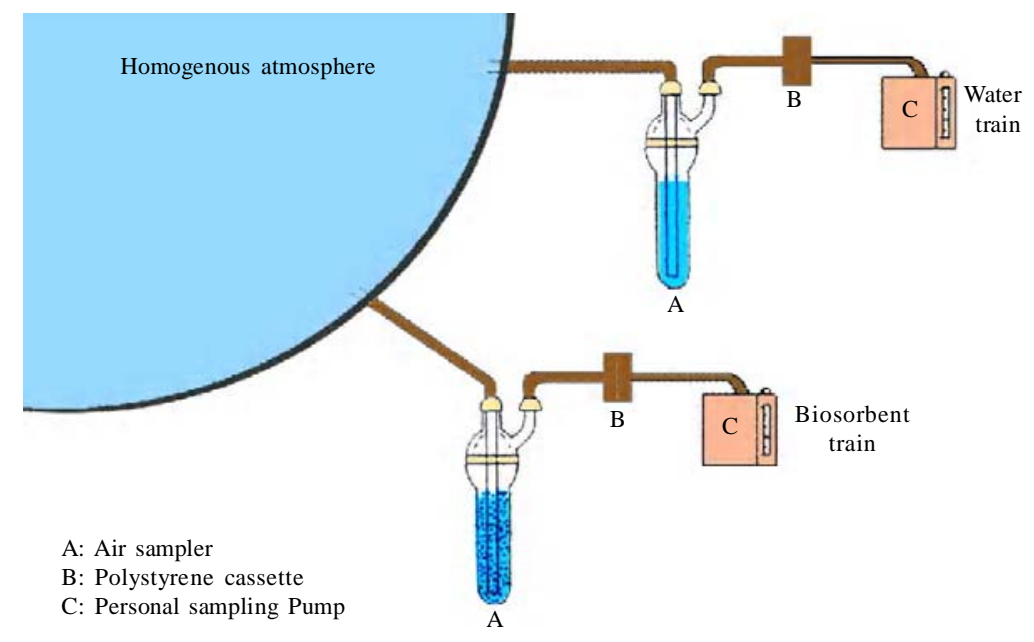

Fig. 2: Set up of the sampling trains 
Optimization of biosorption conditions by Taguchi method

To study the effects of important parameters on airborne Cr (VI) removal, five factors and two levels for each factor were studied by L16 $\left(2^{5}\right)$ Taguchi orthogonal array (Table 1) (Roy, 2001). The analyses of data were done by Qualitek-4 statistical software.

\section{Analytical method}

The metal content in all experiments were measured using a Shimadzu AA 680 non-flame atomic absorption spectrometer. The instrument response was periodically checked with known standards. A calibration curve obtained with a correlation coefficient was 0.98 or greater. The samples were read three times and the mean value, as well as the relative standard deviation was computed. The samples were diluted as required to remain with in the calibration linear range. The $357.7 \mathrm{~nm}$ wavelength was used for chromium ions studied (Cornelis, 1994).

\section{RESULTS AND DISCUSSION}

Primary optimization

Screening test results on $\mathrm{pH}$, pollutant and sorbent concentrations using one factor at a time experimental design was presented in Fig. 3. The plots show the highest $\mathrm{Cr}$ (VI) removal obtained at $\mathrm{pH} 5$, low pollution and medium sorbent concentrations. Other conditions including $\mathrm{pH}$ 6, medium pollutant and high sorbent concentration in the second preference of removal efficiency is considered to be used for secondary optimization. The results presented below represent the mean values of at least three replications.

\section{Secondary optimization}

Table 2 shows the descriptive data and the ANOVA test results for 64 (16 runs with 4 replications) collected samples under the Taguchi experimental design. As indicated, there is no significant difference between the two levels of the main factors on $\mathrm{Cr}$ (VI) removal under the optimized levels ( $\mathrm{P}>0.05$ ), also, there were no significant interactions between factors.

\section{Effect of $p H$}

According to Park et al., 2006. Cr (VI) can be removed from the aqueous solution by nonliving biomass through two mechanisms. In mechanism I (direct reduction), $\mathrm{Cr}$ (VI) is directly reduced to $\mathrm{Cr}$ (III) in the aqueous phase by contact with electron-donor groups of the biomass. However, reduction could occur only under strongly acidic conditions $(\mathrm{pH}<2.5)$. Mechanism II (indirect reduction) consist of three steps: 1. The binding of anionic Cr (VI) ion species to positively charged groups present on the biomass surface; 2 . The reduction of $\mathrm{Cr}$ (VI) to $\mathrm{Cr}$ (III) by adjacent electrondonor groups; 3 . The release of the Cr (III) ions into the aqueous phase due to electronic repulsion between the positively charged groups and $\mathrm{Cr}$ (III) ions or Crbinding. If there is a small number of an electron-donor group in the biomass or protons in the aqueous phase, the chromium bound on the biomass can remain in hexavalent state. Therefore, a portion of mechanisms I

Table 1: Removal percent of Cr(VI) by calcium alginate at different runs according L16 orthogonal array

\begin{tabular}{|c|c|c|c|c|c|c|}
\hline Run & Air Velocity (m/s) & Alginate (g/L) & $\mathrm{pH}$ & Temperature $\left({ }^{\circ} \mathrm{C}\right)$ & $\mathrm{Cr}^{6+}\left(\mu \mathrm{g} / \mathrm{m}^{3}\right)$ & $\mathrm{Cr}^{6+}$ removal (\%) \\
\hline 1 & 1.12 & 10 & 5 & 20 & $<50$ & 36.90 \\
\hline 2 & 1.12 & 10 & 5 & 35 & 50.500 & 32.35 \\
\hline 3 & 1.12 & 10 & 6 & 20 & 50.500 & 41.67 \\
\hline 4 & 1.12 & 10 & 6 & 35 & $<50$ & 39.94 \\
\hline 5 & 1.12 & 20 & 5 & 20 & 50.500 & 39.64 \\
\hline 6 & 1.12 & 20 & 5 & 35 & $<50$ & 35.92 \\
\hline 7 & 1.12 & 20 & 6 & 20 & $<50$ & 50.35 \\
\hline 8 & 1.12 & 20 & 6 & 35 & 50.500 & 44.71 \\
\hline 9 & 2.24 & 10 & 5 & 20 & 50.500 & 42.57 \\
\hline 10 & 2.24 & 10 & 5 & 35 & $<50$ & 44.00 \\
\hline 11 & 2.24 & 10 & 6 & 20 & $<50$ & 34.00 \\
\hline 12 & 2.24 & 10 & 6 & 35 & 50.500 & 54.09 \\
\hline 13 & 2.24 & 20 & 5 & 20 & $<50$ & 30.74 \\
\hline 14 & 2.24 & 20 & 5 & 35 & 50.500 & 36.63 \\
\hline 15 & 2.24 & 20 & 6 & 20 & 50.500 & 34.60 \\
\hline 16 & 2.24 & 20 & 6 & 35 & $<50$ & 29.66 \\
\hline
\end{tabular}


and II is dependent on the biosorption system, such as solution $\mathrm{pH}$, temperature, biomass and $\mathrm{Cr}$ (VI) concentrations (Park et al., 2006).

According to the speciation diagram of Cr (III) complexes in aqueous solutions, from Leyva-Ramos et al. (1995), at $\mathrm{pH} 2$ the molar percentage of $\mathrm{Cr}^{3+}$ is $98 \%$ of the total amount of chromium in solution , while at pH4 this value decreases to about $40 \%$ and almost $60 \%$ is in the ionic form $\mathrm{CrOH}^{2+}$ (and a trace amount of $\mathrm{Cr}(\mathrm{OH})_{4}^{5+}$ ) (Araujo and Teixeira, 1997).

Pandy et al. (2003) reported, adsorptions of chromium by the calcium alginate beads suggest that the functional group present in calcium alginate are the carboxyl groups of gulucronate and mannurate residues (Pandey et al., 2003). When the $\mathrm{pH}$ is higher than 3-4, the carboxyl groups are deportonated and
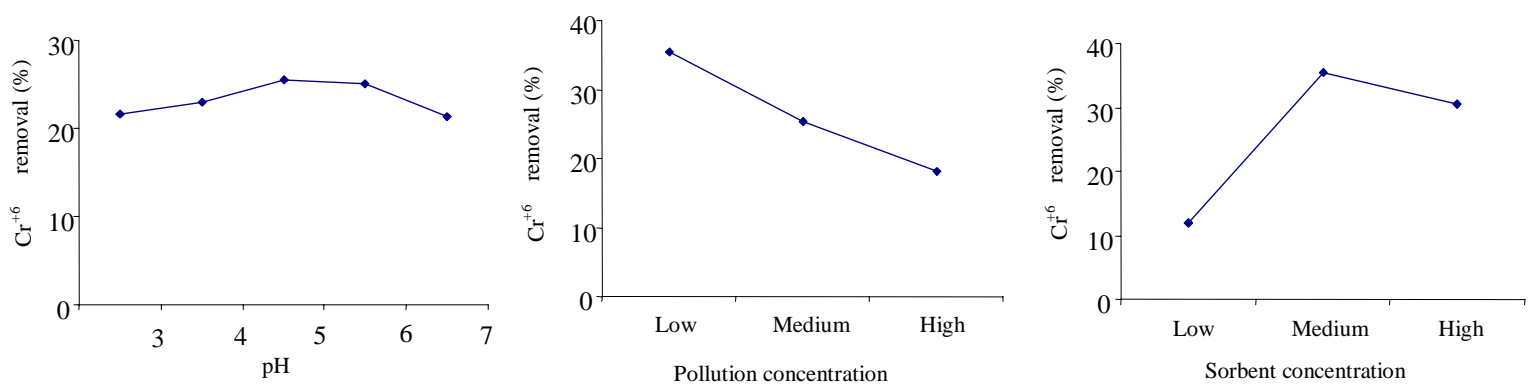

Fig. 3 Screening test results as a function of $\mathrm{pH}$, pollution, and sorbent concentrations at $20 \mathrm{oC}$ and air velocity of $2.24 \mathrm{~m} / \mathrm{s}$

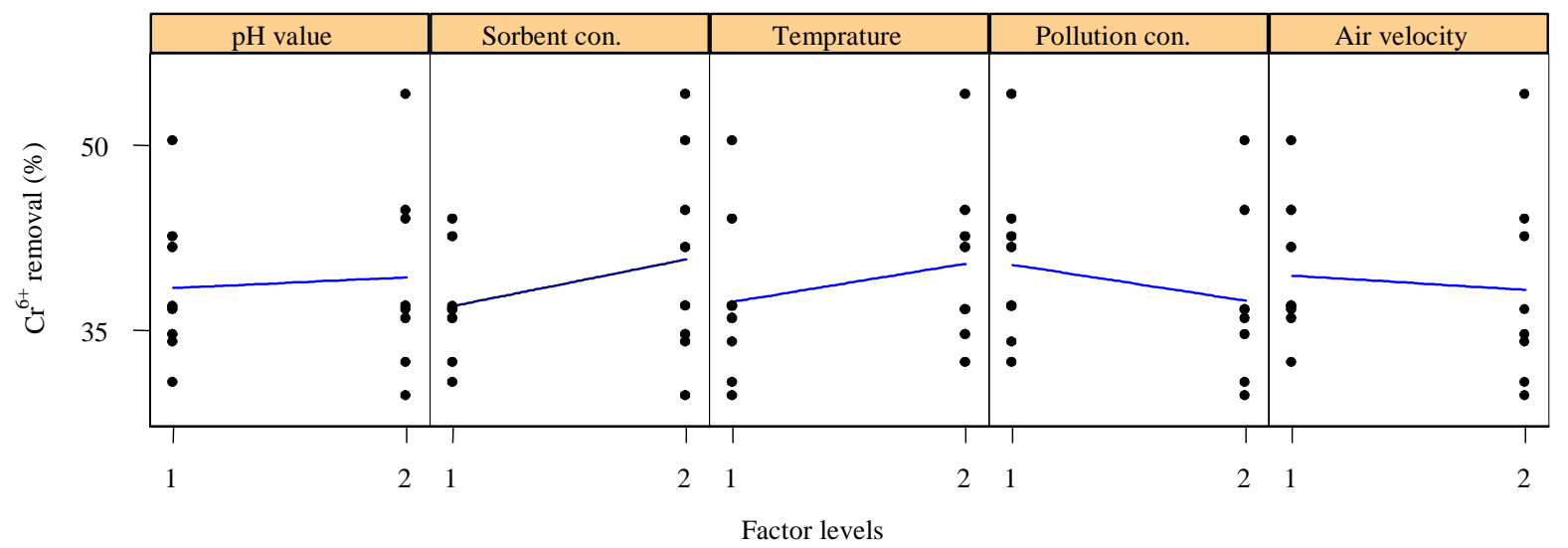

Fig. 4: Effect of air velocity, solution pH, sorbent concentration, pollution concentration, and temperature levels on Cr (VI) removal by alginate beads

Table 2: Descriptive data for 64 samples collected under Taguchi experimental design and its statistical test result

\begin{tabular}{|c|c|c|c|c|}
\hline Factor & Levels & Cr (VI) removal (\%) & SD & P-Value \\
\hline \multirow[t]{2}{*}{$\mathrm{pH}$} & 1 & 38.43 & 6.20 & 0.83 \\
\hline & 2 & 39.29 & 7.89 & \\
\hline \multirow[t]{2}{*}{ Temperature } & 1 & 37.31 & 6.86 & 0.46 \\
\hline & 2 & 40.41 & 6.96 & \\
\hline \multirow[t]{2}{*}{ Sorbent concentration } & 1 & 36.97 & 4.51 & 0.36 \\
\hline & 2 & 40.75 & 8.51 & \\
\hline \multirow[t]{2}{*}{ Pollution concentration } & 1 & 40.32 & 6.93 & 0.49 \\
\hline & 2 & 37.41 & 6.93 & \\
\hline \multirow[t]{2}{*}{ Air velocity } & 1 & 39.44 & 5.79 & 0.78 \\
\hline & 2 & 38.28 & 8.17 & \\
\hline
\end{tabular}


left with negative charge. Therefore, at pHs above 3-4, the negatively charged carboxylate group may attract the positively charged chromium ions consequently binding and removing the $\mathrm{Cr}(\mathrm{VI})$ ions from solution. At pHs lower than 3-4, the carboxyl groups become porotonated and no longer attract the positively charged chrome ions (Gardea-Torresdey et al., 1996).

Araujo and Teixiera studied the effect of $\mathrm{pH}$ on metal adsorption at 2-4 and reported that there was a higher trivalent chromium adsorbed at $\mathrm{pH} 4$ (Araujo and Teixeira, 1997).

Gardea-Torresdey et al. (2002) reported the same result. They showed that the unmodified alfalfa biomass (this biomaterial binds predominantly through carboxyl ligands) and carboxyl ion exchange resin (WTO1S) displayed similar $\mathrm{pH}$ dependent trends and the optimal binding $\mathrm{pH}$ for these biosorbents was between 5 and 6 (Gardea-Torresdey et al., 2002) (Fig . 4).

\section{Effect of sorbent concentration}

As Table 2 and Fig. 4 show, increasing alginate concentration between 3.3 to $20 \mathrm{mg} / \mathrm{mL}$ enhanced Cr (VI) removal, however, there is no significant difference between the chromium removal in concentrations 10 and $20 \mathrm{mg} / \mathrm{mL}$ ( $\mathrm{P}>0.05)$. Chand et al. reported that, higher sorbent concentration gave the greater $\mathrm{Cr}$ (VI) removal percent. However, up to a certain level and beyond that, more or less constant removal was observed (Chand et al., 1994).

Results in general, have revealed that the Cr (VI) removal from air is not strongly affected by the sorbent concentration at the range of 10 and $20 \mathrm{mg} / \mathrm{mL}$.

\section{Effect of temperature}

The temperature of the adsorption medium could be important for energy demands mechanisms in metal biosorption. Energy-independent mechanisms are less likely to be affected by temperature since the processes responsible for biosorption are largely physicochemical in nature (Kacer et al., 2002).

As it shown in Table 2 and Fig. 4, maximum binding capacity values were mostly at $35^{\circ} \mathrm{C}$ but the ANOVA test result shows no statistical significant difference between the two levels (40.41 \pm 6.96 vs. $37.31 \pm 6.86)$ $(\mathrm{P}>0.05)$. Thus, the biosorption of $\mathrm{Cr}(\mathrm{VI})$ by alginate appeared to be temperature independent in the range of 20 to $35^{\circ} \mathrm{C}$.

Araujo and Teixeira reported that the higher temperature (in the range of 10 to 27) favors the sorption of Cr (III) on calcium alginate beads (Araujo and Teixeira, 1997), while our results and the results reported by Kacar et al. (2002) indicated that adsorption of Cr(VI) ions on calcium alginate beads was not significantly dependent on temperature at range $15-35^{\circ} \mathrm{C}$ (Kacer et al., 2002). In nature, biosorption is largely physicochemical and an energy-independent mechanism, therefore, it is less likely affected by temperature.

\section{Effect of air pollution concentration}

Airborne Cr (VI) with different concentrations ( $<50$ and $50-500 \mu \mathrm{g} / \mathrm{m}^{3}$ ) were treated to evaluate the influence of pollution concentration on sorption behavior of alginate beads.

As depicted in Fig. 4, although an increase in Cr (VI) concentration had no drastic effect on removal efficiency (40.32 \pm 6.93 vs. 37.41 \pm 6.93 ), higher adsorption yields were observed at lower concentration of metal ions. Similar trend has been reported by other researchers (Chand et al., 1994; Kacer et al., 2002; Ahalya et al., 2005; Tirgar et al., 2006b ).

\section{Effect of air velocity}

In order to investigate the effect of contact time and agitation rate on $\mathrm{Cr}$ (VI) removal, polluted air samples were passed through the sorbent medium with different air velocity. Fig. 4 and Table 2 show that Cr (VI) uptake decrease with the increase in air velocity, however, there is no statistical significant difference between $\mathrm{Cr}$ (VI) uptake at 1.12 and $2.24 \mathrm{~m} / \mathrm{s}(\mathrm{P}>0.05)$. Consequently, it can be concluded that, however agitation facilitates a proper contact between the metal ions in solution and biomass binding sites and thereby it promotes effective transfer of sorbate ions to the sorbent sites (Ahalya et al., 2005), higher air velocity leads to reduction of contact time (passing faster through sorbent medium) and less adsorption.

\section{CONCLUSION}

It can be concluded that, biosorption is an efficient process for the removal of $\mathrm{Cr}$ (VI) mist in a wide range of pollution concentration. Obviously, higher removal efficiency could be obtainable, using suitable alginate producer biomass or alginate derivatives.

Based on our experiments, the optimum condition with maximum yield for removal of $\mathrm{Cr}$ (VI) by alginate beads are as follows:

Lower levels of air velocity, and pollution concentration, 
Higher levels of $\mathrm{pH}$ sorbent concentration and temperature.

Also, it was shown that proposed airborne Cr (VI) removal system can work in broad range of working conditions that makes it more feasible at industrial scale.

\section{ACKNOWLEDGEMENTS}

Special thanks to School of Public Health and Public Health Research Institute, Tehran University of Medical Sciences for providing funding to this research (Grant Number 2655). Likewise, to Mrs. P. Jamee for her valuable assistance in samples analyses.

\section{REFERENCES}

Abdel-Ghani, N. T.; Elchghaby, G. A., (2007). Influence of operating conditions on the removal of $\mathrm{Cu}, \mathrm{Zn}, \mathrm{Cd}$ and $\mathrm{Pb}$ ions from wastewater by adsorption. Int. J. Environ. Sci. Tech., 4 (4), 451-456 (6 pages).

Ahalya, N.; Kanamadi, R. D.; Ramachandra, T. V., (2005). Biosorption of chromium (VI) from aqueous solutions by the husk of Bengal gram (Cicer arientium). J. Biotech., 8 (3), 258-264 (7 pages).

Aliabadi, M.; Morshedzadeh, K.; Soheyli, H., (2006). Removal of hexavalent chromium from aqueous solution by Lignocellulosic solid wastes. Int. J. Environ. Sci. Tech., 3 (3), 321-325 (5 pages).

Araujo, M. M.; Teixeira, J. A., (1997). Trivalent chromium sorption on alginate beads. Int. Biodeterior. Biodegrad. 40 (1), 63-74 (12 pages).

Ashley, K.; Howe, A. M.; Demang, M.; Nygren, O., (2003). Sampling and analysis consideration for the determination of hexavalent chromium in workplace air. J. Environ. Monit., 5 (5), 707-716 (10 pages).

Babel, S.; Opiso, E. M., (2007). Removal of Cr from synthetic wastewater by sorption into volcanic ash soil. Int. J. Environ. Sci. Tech., 4 (1), 99-108 (10 pages).

Chand, S.; Agarwal, V. K.; Kumar, P., (1994). Removal of hexavalent chromium form waste water by adsorption. Indian J. Environ. Health, 36 (3), 151-158 (8 pages).

Cloacae, E.; Sethuraman, P.; Balasubramanian, N., (2010). Removal of $\mathrm{Cr}$ (VI) from aqueous solution using Bacillus subtilis, Pseudomonas. Int. J. Eng. Sci. Tech., 2 (6), 18111825 (15 pages).

Cornelis, R., (1994). Chromium in Herber R. F. M. Stoeppler M. Trace element analysis in biological. Elsevier science, Netherlands, 343-349 (7 pages).

Costa, M.; Klein, C. B., (2006). Toxicity and carcinogenicity of chromium compounds in humans. Critical Review in Toxicol., 36 (2), 155-163 (9 pages).

Gardea-Torresdey, J. L.; Tiemann, K. J.; Gonzalez, J. H.; CanoAguilera, I.; Henning, J. A.; Townsend. M. S., (1996). Removal of nickel ions from aqueous solution by biomass and silicaimmobilized biomass of Medicago Sativa (alfalfa). J. Hazard. Mater., 49 (2-3), 205-216 (12 pages).

Gardea-Torresdey, J. L.; Dokken, K.; Tiemann, K. J.; Parsons, J. G.; Ramos, J.; Pingitore, N. E.; Gamez, G., (2002). Inferared and X-ray adsorption spectroscopic studies on the mechanism of chromium (III) binding to alfalfa biomass. Microchem. J., 71 (2-3), 157-166 (10 pages).
Göksungur, Y.; Üren, S.; Güvenç, U., (2003). Biosorption of copper ions by caustic treated waste baker's yeast biomass. Turk. J. Biol., 27 (1), 23-29 (7 pages).

Goyal, P.; Sharma, P.; Srivastava, S.; Srivastava, M. M., (2008). Saraca indica leaf powder for decontamination of $\mathrm{Pb}$ : Removal, recovery, adsorbent characterization and equilibrium modeling. Int. J. Environ. Sci. Tech., 5 (1), $27-$ 34 ( 8 pages).

Guertin, J.; Jacobs, J. A.; Avakian, C. P., (2005). Chromium (VI) handbook. CRC Press, Boca Raton, 2.

Hara, T.; Hoshuyama, T.; Takahashi, K.; Delgermaa, V.; Sorahan, T., (2010). Cancer risk among Japanese chromium platers, 1976-2003. Scand. J. Work Environ. Health, 36 (3), 216-221 (6 pages).

Ibanez, J. P.; Umetsu, Y., (2002). Potential of portonated alginate beads for heavy metals uptake. Hydrometallurgy, 64 (2), 89-99 (11 pages).

Kacar, Y.; Arpa, C.; Tan, S.; Denizli, A.; Genc, O.; Arica, M. Y., (2002). Biosorption of $\mathrm{Hg}$ (II) and Cd (II) from aqueous solutions: Comparison of biosorptive capacity of alginate and immobilized live and heat inactivated Phanerochaete Chrysospoium. Process Biochem., 37, 601-610 (10 pages).

Kumar, S.; Sathwara, N. G.; Gautam, A. K.; Agarwal, K.; Shah. B.; Kulkarni, P. K.; Patel, K.; Patel, A.; Dave, L. M.; Parikh, D. J.; Saiyed, H. N., (2005). Seman Quality of Industrial Workers Occupationally Exposed to Chromium. J. Occup. Health., 47 (5), 424-430 (7 pages).

Kuo, Y. M.; Wang, C. S., (1999). Concentration effect of chromic acid solutions on the enrichment of $\mathrm{Cr}$ (VI) in droplets from bursting bubbles. Aerosol Sci. Tech., 31, 275285 (11 pages).

Kuo, Y. M.; Wang, C. S., (2002). Effect of rise distance on droplet generated from bubble bursting on the surface of chromic acid solutions. AIHA J., 63 (1), 5-10 (6 pages).

Leyva-Ramos, R.; Fuentes-Rubio, L.; Guerrero-Coronado, R.; Mendoza-Barron, J., (1995). Adsorption of trivalent chromium from aqueous solutions onto activated carbon. J. Chem. Tech. Biotech., 62, 64-67 (4 pages).

Nickens, K. P.; Patierno, S. R.; Ceryak, S., (2010). Chromium genotoxicity: A double-edged swerd. Chemico-Biological Interactions, 188 (2), 276-288 (13 pages).

Nameni, M.; Alavi Moghadam, M. R.; Arami, M., (2008). Adsorption of hexavalent chromium from aqueous solutions by Wheat Bran. Int. J. Environ. Sci. Tech., 5 (2), 161-168 (8 pages).

Nwachukwu, M. A.; Feng, H.; Alinno, J., (2010). Assessment of heavy metal pollution in soil and their implications within and around mechanic villages. Int. J. Environ. Sci. Tech., 7 (2), 347-358 (12 pages).

OSHA, (2006). Health effects of hexavalent chromium. Occupational Safety and Health Administration, Occupational Safety and Health Administration, Washington, 1-2 (2 pages).

Pandey, A. K.; Pandey, S. D.; Misra, V.; Srimal, A. K., (2003). Removal of chromium and reduction of toxicity to Microtox system from tannery by the use of calcium alginate beads containing humic acid. Chemosphere, 51 (4), 329-333 (5 pages).

Pandey, P. K.; Sharma, S. K.; Sambi, S. S., (2010). Kinetics and equilibrium study of chromium adsorption on zeoliteNaX. Int. J. Environ. Sci. Tech., 7 (2), 395-404 (10 pages). 
Park, D.; Yun, Y. S.; Park, J. M., (2004). Reduction of Hexavalent Chromium with Brown seaweed Ecklonia. Biomass. Environ. Sci. Tech., 38 (18), 4860- 4864 (5 pages).

Park, D.; Park, J. M., (2006). Removal of Hexavalent Chromium by Using Biomass. Korean. Chem. Eng. Res., 44, 107-113 ( 7 pages).

Park, D.; Yun, Y. Park, J. M., (2006). Mechanisms of the removal of hexavalent chromium by biopolymers or biomaterial -based activated carbon. J. Hazard. Mater., 137 (2), 1254-1257 (5 pages).

Rafati, L.; Mahvi, A. H.; Asgari, A. R.; Hosseini, S. S., (2010). Removal of chromium (VI) from aqueous solutions using Lewatit FO36 nano ion-exchange resin. Int. J. Environ. Sci. Tech., 7 (1), 147-156 (10 pages).

Roy, R., (2001). Design of experiments using the Taguchi approach, Willy, New York, USA .

Tirgar, A.; Golbabei, F.; Nourijelyani, K.; Shahtaheri, S. J.; Ganjali, M. R.; Hamedi, J., (2006a). Design and performance of chromium mist generator. J. Braz. Chem. Soc., 17 (2), $342-347$ (6 pages).

Tirgar, A.; Golbabei, F.; Hamedi, J., Nourijelyani, K.; Shahtaheri, S. J.; Moosavi, S. R., (2006b). Removal of airborne hexavalent chromium mist using chitosan gel beads as a new control approach. Int. J. Environ. Sci. Tech., 3 (3), 305313 (9 pages).

Tirgar, A.; Golbabei, F.; Nourijelyani, K.; Kanzadeh, A. F.; Shahtaheri, S. J.; Ganjali, M. R.; Hamedi, J., (2007). Evaluation of parameters influencing hexavalent chromium mist sampling: A full factorial design. Iran. J. Chem. Chem. Eng., 26 (4), 115-121 (7 pages).

Veglio, F.; Espoito, A.; Reverberi, A. P., (2002). Copper adsorption on calcium alginate beads: Equilibrium $\mathrm{pH}$-related model. Hydrometallurgy, 65 (1), $43-57$ (15 pages).

Vinodhini, V.; Das, N., (2010). Relevant approach to assess the performance of sawdust as adsorbent of chromium (VI) ions from aqueous solutions. Int. J. Environ. Sci. Tech., 7 (1), 85-92 (8 pages).

\section{AUTHOR (S) BIOSKETCHES}

Tirgar, A., MSPH., Ph.D., Assistant professor, Department of Social Medicine, School of Medicine, Babol University of Medical Sciences, Babol, Iran. Email: a_tirgar@yahoo.com

Golbabaei, F., MSPH., Ph.D., Professor, Department of Occupational Health, School of Public Health, Tehran University of Medical Sciences, Tehran, Iran. Email: fgolbabaei@sina.tums.ac.ir

Hamedi, J., Ph.D., Assistant professor, Microbial Biotechnology Laboratory, School of Biology, College of Science, University of Tehran, Tehran, Iran. Email: jhamedi@khayam.ut.ac.ir

Nourijelyani, K., MSPH., Ph.D., Associate professor, Department of Epidemiology and Biostatistics, School of Public Health, Tehran University of Medical Sciences, Tehran, Iran. Email: nouri4@yahoo.com 